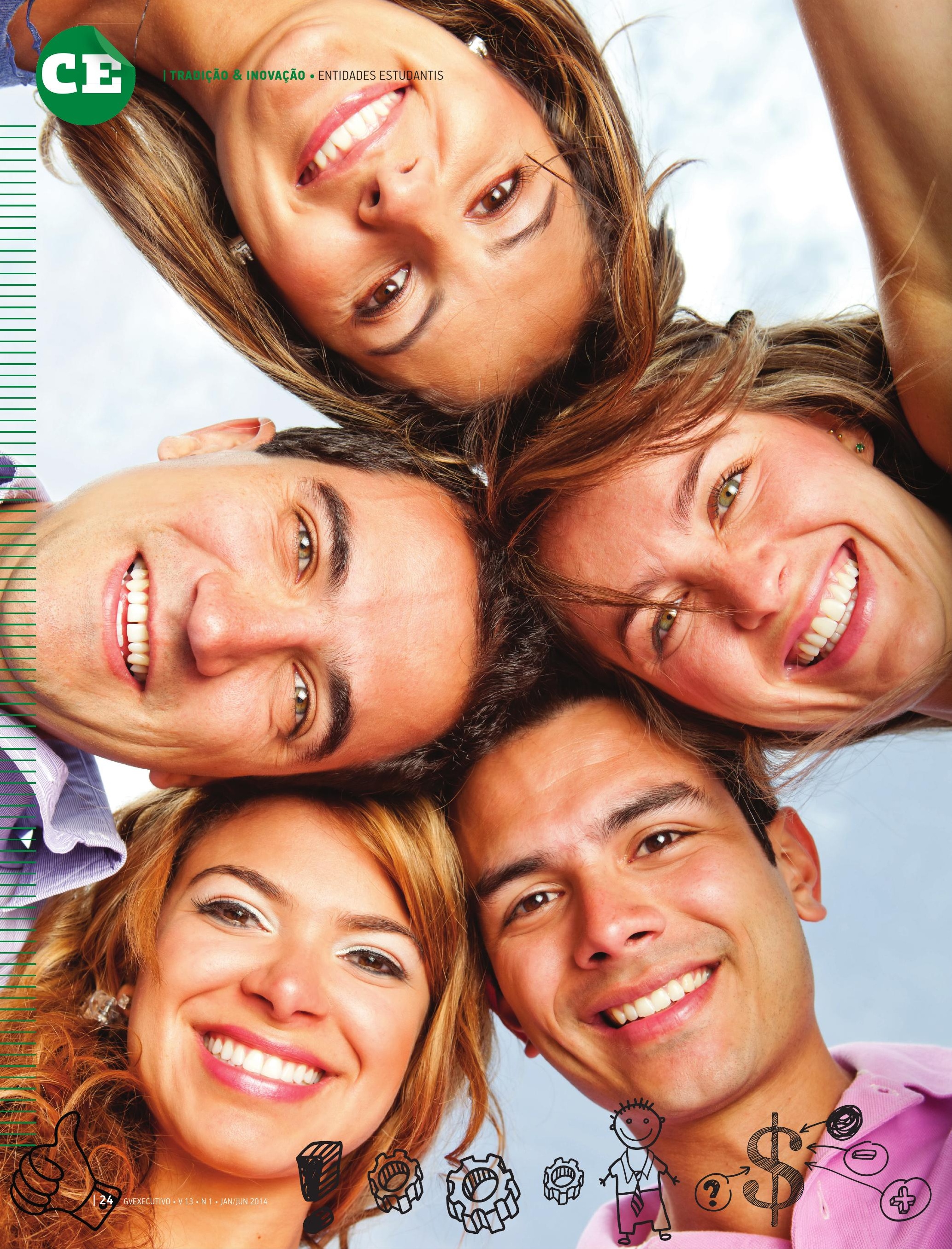




\section{ENTIDADES ESTUDANTIS: LABORATÓRIOS DE PROFISSIONAIS}

\section{INOVAÇÃO, IRREVERÊNCIA E OUSADIA MARCAM A VIDA ESTUDANTIL DA FGV-EAESP NESSES 60 ANOS DE HISTÓRIA}

| POR PATRICIA TAVARES

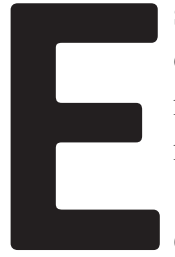

screver este breve apanhado sobre as entidades estudantis e seu impacto na vida dos alunos revelou-se um exercício muito gratificante de resgate à memória de três gerações da EAESP.

Sempre refletindo o momento histórico do país, essas instituições revelam a força empreendedora dos estudantes e as diferenças geracionais no estabelecimento de prioridades.

\section{OS PRIMEIROS 20 ANOS (1954 - 1974)}

Imagine uma turma com 240 alunos em que todos se conhecem. Foi assim o início da história da EAESP.

Aúnica entidade estudantil da Escola era o Centro Acadêmico de Administração de Empresas (CAAE), que cuidava de assuntos acadêmicos e desportivos.

Os estudantes desportistas participavam com muita dificuldade dos jogos organizados pela Federação Universitária Paulista de Esporte (FUPE) (o primeiro time de futebol teve de "catar" 11 jogadores - realidade presente até minha época de aluna, nos fins da década de 1980). Ainda assim, bons resultados foram conquistados na área esportiva por méritos individuais. A primeira medalha da FGV veio com o $2^{\circ}$ lugar na modalidade levantamento de peso, conquistada por Abilio Diniz, em 1956. Já na década de 1960, a equipe de polo aquático (isso mesmo!) da GV consagrou-se campeã nos Jogos Universitários Brasileiros (JUBs). Isso voltou a acontecer em fins da década de 1980.

Segundo Francisco Mazzuca, ex-diretor da Escola e diretor social do CAAE na época em que Eduardo Suplicy era presidente da entidade (entre 1963 e 1964), o centro organizava festas e espaços de discussão sobre política. Havia maior interesse e envolvimento com essa última questão em função da situação do país. Em março de 1964, houve uma assembleia no restaurante da EAESP com maciça participação de alunos e professores para debater as implicações do golpe militar. Guardadas as proporções e diferenças de contexto, a Escola voltou a se reunir para discutir e entender as movimentações de junho de 2013.

Fernando Carmona, ex-diretor da EAESP entre 1965 e 1966, também teve participação ativa durante seu período como aluno - foi diretor cultural do Centro Acadêmico e trouxe shows de diversos artistas para o auditório, como o de Geraldo Vandré, um dos maiores nomes da música popular brasileira e que chegou a ser perseguido no período da ditadura militar devido às suas composições.

No ano de 1970, surge uma nova entidade - não consistiu em uma iniciativa dos estudantes, mas foi abrigada por eles: a Associação Internacional de Estudantes em Ciências Econômicas e Comerciais (AIESEC), organização de jovens universitários de todo o mundo, desembarcou aqui para proporcionar experiências internacionais, promovendo intercâmbios culturais. Desde então, a entidade permanece na Escola oferecendo conhecimento sobre diversos países, desenvolvimento de habilidades e troca de experiências.

Essa movimentação cultural também foi marcada pelo Cineclube GV — que foi inaugurado em 1974 e teve grande impacto e visibilidade na cidade de São Paulo (sua história está retratada na última edição da $G V$-executivo - volume 12 , número 2, 2013) - e, até hoje, realiza shows dos mais variados artistas, bem como festivais de arte e música promovidos pelos alunos.

\section{ANOS DE FERMENTAÇÃO (1974 - 1994)}

Durante esse período, o CAAE promovia atividades sociais, culturais, esportivas e políticas, dentro e fora da Escola, além 


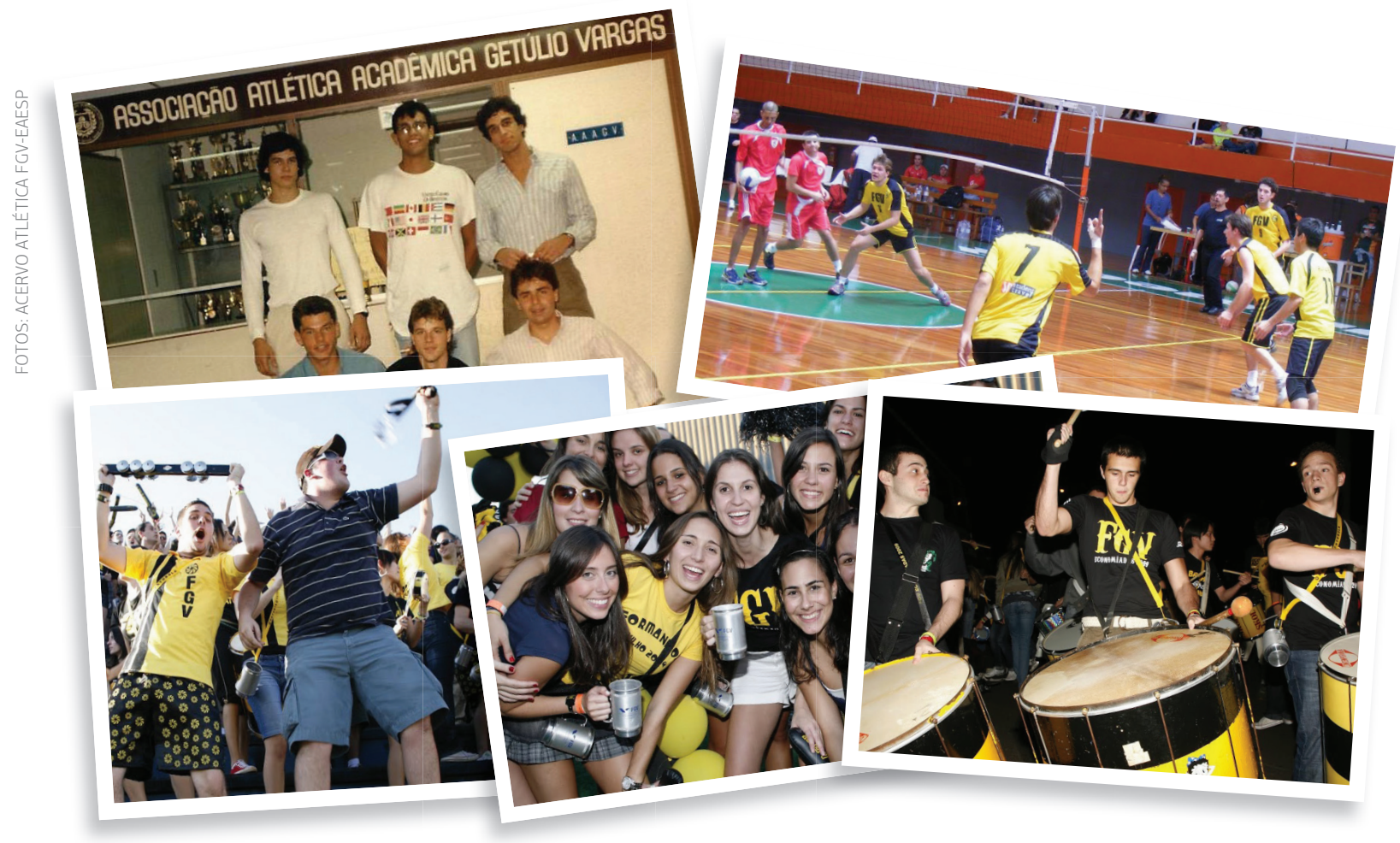

Primeira imagem à esquerda: Sede da Atlética em 1987. Demais: GVnianos no Economíadas, competição entre as principais faculdades de Economia e Administração do Estado de São Paulo

do Cineclube. Elas permitiam aos alunos não apenas aproveitar a convivência estudantil, mas também lapidar habilidades importantes para o empreendedorismo e a vida corporativa. Várias iniciativas de estudantes geraram spin offs no mundo real, ou seja, novas empresas nasceram a partir dessas ações.

A lei federal 6.251, de 1975, desvinculava a prática e a organização do esporte universitário dos centros acadêmicos. A Associação Atlética Acadêmica Getulio Vargas (AAAGV) foi constituída oficialmente (com CNPJ) apenas em 1986, quando a chapa vencedora assumiu a gestão do Diretório Acadêmico (DA) (antigo CAEE) e regularizou a sua situação.

Foi nesse ano que muita coisa mudou no DA: uma eleição que contou com 879 votos dos 1.200 alunos e elegeu uma chapa que fez enormes reformas físicas e de gestão. Começou ali um período no qual os estudantes contaram com grandes benefícios e que teve foco em festas diferenciadas. A Gioconda na época organizada por uma turma do $2^{\circ}$ semestre do curso de Administração de Empresas apenas para os amigos - foi incorporada pelo DA em 1991 (em sua $5^{\text {a }}$ edição) e tornou-se uma das maiores festas universitárias da cidade.

A eleição seguinte do DA, em 1988, foi acirrada: um grupo querendo resgatar o lado mais politizado da entidade e o outro, que já a liderava, o qual conseguiu se reeleger.

O candidato não eleito, Rogério Chér, ficou realmente chateado com a situação, bem como com a incapacidade de ajudar seu pai e avô nos negócios da família. As aulas e os casos analisados durante o curso não correspondiam aos desafios enfrentados por empresas brasileiras de pequeno e médio porte. Os estágios de meio período disponibilizados para estudantes da GV não eram tão cobiçados (os melhores exigiam que se trabalhasse período integral).

Foi aí que Murilo Nahas, um dos membros do grupo político de Chér na Escola (na época, isso existia), convidou-o para uma conversa com o representante da Câmara de Comércio e Indústria Franco-Brasileira. Ele queria implementar uma Junior Enterprise no país, modelo de atuação existente desde 1967 na França. Rogério saiu da reunião certo de ter descoberto o que poderia ser um grande espaço de aprendizagem para os alunos e de apoio para os empresários brasileiros de pequeno e médio porte. Convocou o grupo que não se elegeu para o DA e organizaram a primeira Empresa Júnior (EJ) do Brasil. Detalhe: esse foi o nome escolhido, porque tinha melhor sonoridade em Português. Chér também ajudou a estruturar o movimento EJ Brasil, o maior e mais organizado do mundo, com federações estaduais e a Brasil Júnior como órgãos normativos.

Desde a sua fundação, no primeiro semestre de 1989 , a EJ serviu - e ainda serve - de inspiração para a implantação e atuação de várias entidades, não apenas na FGV. A Júnior Pública (JP) acabou sendo um desdobramento quase que natural da Escola, que possui habilitação em Administração Pública. 


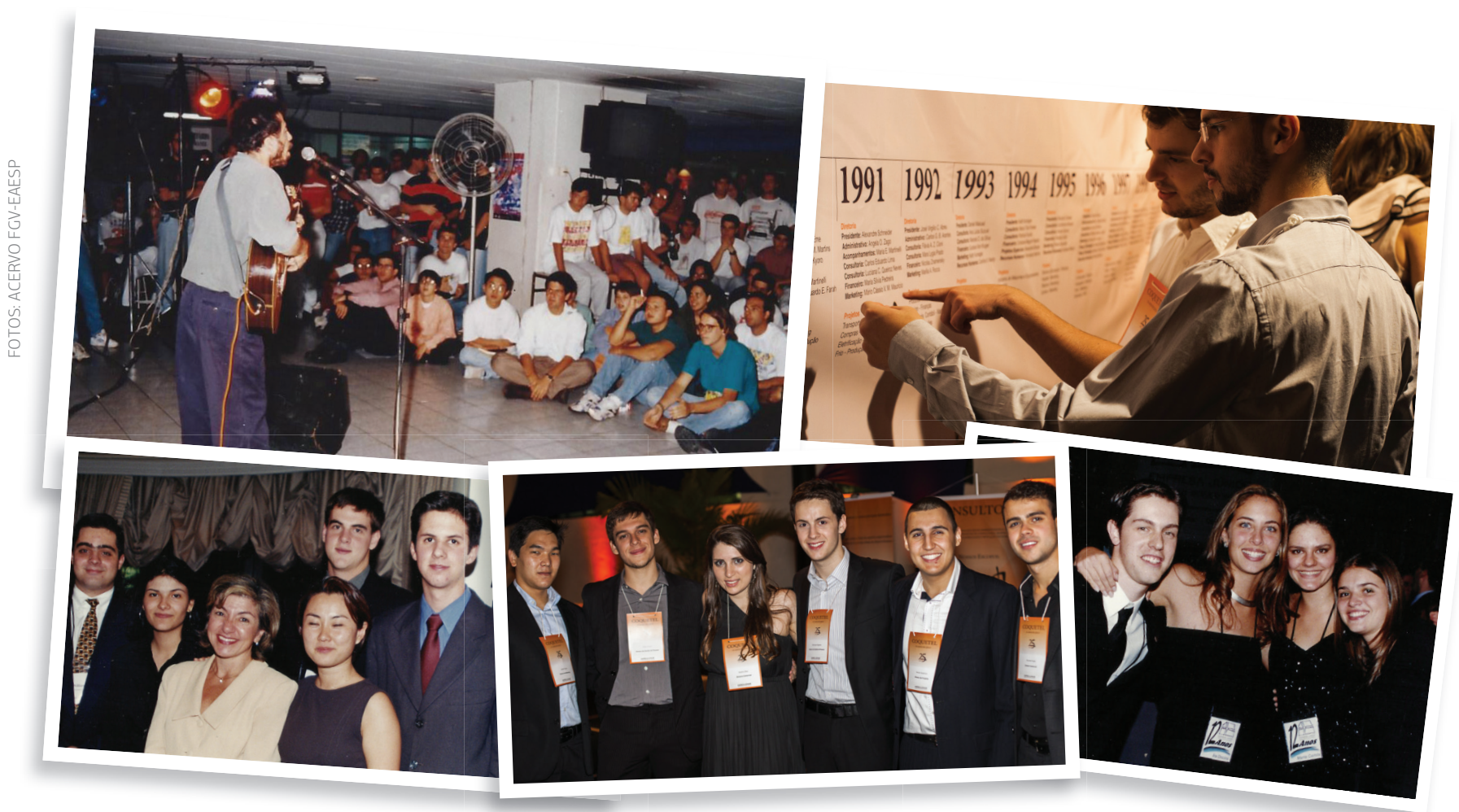

Primeira imagem à esquerda: Show do Tom Zé no Diretório Acadêmico na década de 1990. Demais: Eventos promovidos pela Empresa Júnior (gestões dos anos 2000 e 2013)

Nessa mesma época, um trio de amigos (Conrado Schlochauer, Alexandre Santille e Fernando Jucá) criou uma série de eventos que proporcionavam contato dos alunos com o mercado de administração, por meio de palestras com profissionais de áreas que não eram exploradas no curso. Eles montaram uma empresa ao sair da faculdade e versões diferentes desse tipo de evento - o qual aconteceu entre 1990 e 1992 - foram instauradas em anos posteriores, como o Café \& Negócios (pela EJ), promovendo debates com empresários e empreendedores sobre diversos temas do mundo da gestão.

\section{MULTIPLICAÇÃO DE FRENTES (1994 - 2014)}

Foram muitas as entidades criadas desde então, embora nem todas permaneçam ativas. O "Cia do Kumesso" (19992002) foi um grupo de teatro montado pelos alunos. Uma das ex-integrantes da Cia hoje é dramaturga e, apesar de não existir mais, essa iniciativa levou alguns alunos a buscar cursos profissionais de atuação, o que, certamente, potencializou suas habilidades interpessoais. O Coral da GV, o Conexão Social (programa que incentiva os alunos a realizarem ações sociais e transformarem a realidade para melhor), o Prêmio Gestão Empresarial Rio Sul (organizado pela EJ por três anos), a sede da Federação Nacional dos Estudantes de Administração (FENEAD) e a implantação do Prêmio FENEAD, que, por três anos, foi organizado pelos alunos da GV, são exemplos da efervescência de criatividade e execução dos estudantes apoiados pelas entidades estudantis. A participação em uma dessas instituições sempre serviu de inspiração para a criação de outras iniciativas.

Os espaços de experimentação e aprendizado - e a consequente ampliação de horizonte dos alunos — mostram amadurecimento se comparados com as décadas anteriores. Hoje existe a Liga das Entidades (LIDEN) para coordenar as ações e calendários das 11 entidades estudantis da FGV: EJ, JP, DA, AAAGV, RH Junior, AIESEC, Consultoria Júnior de Economia, Incubadora Tecnológica de Cooperativas Populares, Gazeta Vargas, Conexão Social e Centro de Estudos Jurídicos Júnior (CEJUR). Ainda que uma parte dos alunos não se envolva em atividades extracurriculares ou representação política de seus interesses, essas entidades estão presentes na articulação e viabilização de inovações ao corpo discente.

Uma característica que percebi ao levantar os dados para este artigo é a maciça presença de alunos forasteiros nessas instituições. A primeira diretoria da EJ contava com cinco, dos sete diretores, nascidos fora de São Paulo. Felipe Girão, ex-diretor da EJ e organizador de duas edições do Prêmio Gestão Empresarial Rio Sul, comentou que, em todas as entidades de sua época, o contingente de alunos de outras cidades foi sempre maior. Hoje ainda é assim. Aparentemente, as entidades estudantis são mais do que espaços de formação da vida profissional dos estudantes, tornam-se também a "família" dos que estão longe de casa.

PATRICIA TAVARES > Professora da FGV-EAESP> patricia.tavares@fgv.br 